\title{
Compliance e a cultura de paz
}

\author{
Compliance and culture of peace
}

\section{CLAUDIO CARNEIRO'}

professorclaudiocarneiro@gmail.com

GALILEU - REVISTA DE DIREITO E ECONOMIA - e-ISSN 2184-1845

Volume XX $\cdot 1^{\text {st }}$ January Janeiro $-30^{\text {TH }}$ June Junho $2019 \cdot$ pp. 37-58

DOI: ???

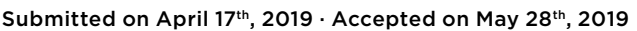

Submetido em 17 de Abril, 2019. Aceite a 28 de Maio, 2019

RESUMo O Direito à Paz como Direito Fundamental tem origem em um movimento que vem ao encontro de outro que se denomina a Era do Compliance. A partir desses dois movimentos que se exteriorizam como a Cultura de Paz e a Cultura de Integridade, busca-se estabelecer no presente texto uma relação existente entre os fins colimados por ambos através de um Sistemas de Gestão de Compliance. Esse sistema que envolve a boa governança pública e privada, pode ser considerado como uma das ferramentas de se viabilizar o Direito à Paz. A correlação se estabelece com base nos movimentos sociais, na classificação dos direitos fundamentais e, ainda, pela necessidade de uma mudança comportamental que se solidifica com a educação e a ética. Os Programas de Compliance, enquanto sistemas de gestão, permitem um melhor controle e capacitação de todos os atores sociais envolvidos que vão desde pessoas à Organizações (públicas ou privadas).

PALAVRAS-CHAVE Compliance, Cultura de Paz, Direito Fundamental.

ABSTRACT The Right to Peace as Fundamental Right originates in a movement that comes throught another that is called the Age of Compliance. From these two movements that are expressed as the Culture of Peace and the Culture of Integrity, it is sought to establish in the present text a relationship between the ends collimated by both through a Compliance Management Systems. This system, which involves good public and private governance, can be considered as one of the tools to make the Right to Peace viable. Correlation is established based on social movements, the classification of fundamental rights, and the

1 Pós-Doutor pela Universidade Nova de Lisboa. Advogado. Sócio do Claudio Carneiro Advogados Associados. Professor do Curso de Mestrado da UniFG/BA. Professor convidado do Curso de Mestrado da Universidade Autónoma de Lisboa. Vice-presidente da Ethical \& Compliance International Institute. Professor da Fundação Getúlio Vargas. Presidente da Comissão de Compliance do IAB (Brasil) e Presidente da Comissão de Direito à Educação da $\mathrm{OAB} / \mathrm{RJ}$. 
need for change behavior that solidifies with education and ethics. Compliance Programs, as management systems, allow better control and empowerment of all social actors involved ranging from individuals to Organizations (public or private).

KEYWorDS Compliance, Culture of Peace, Fundamental Law.

\section{Introdução}

Catalogar os desafios enfrentados na vigência do século XXI não é uma tarefa simples, pois variáveis importantes como, por exemplo, a revolução digital, o combate à corrupção e as Guerras, provocaram importantes mudanças na sociedade. Contudo, a corrupção institucionalizada e a violação dos direitos humanos decorrentes das Guerras foram os fatores que mais provocaram prejuízos a todos os atores da sociedade, daí o esforço significativo das autoridades públicas de diversos países para combatê-las. Por esses e tantos outros motivos, acreditamos ser possível afirmar que o presente século vem sendo reconhecido como a Era do Compliance.

O mundo globalizado possibilitou que as mazelas desencadeadas por eventos danosos que ocorreram em diferentes continentes, se propagassem de forma veloz passando a exigir uma mudança comportamental, tanto do Poder Público, quanto da sociedade e da iniciativa privada. Referimo-nos, nesse ponto, aos escândalos de corrupção e as condições desumanas que foram noticiadas na mídia mundial, como por exemplo, o caso crônico da África e dos refugiados da Guerra da Síria.

Nesse contexto, a correlação entre a Cultura do Compliance e a Cultura de Paz pode causar estranheza, mas ao contrário do que possa parecer a relação é próxima e se justifica pelo fato de que ambos são movimentos que buscam, respectivamente, o direito à Boa Governança e à Paz. Ademais, não é por acaso que esses direitos vêm sendo classificados pela doutrina moderna como novas dimensões de direitos fundamentais.

A partir dos citados movimentos que se exteriorizam com a Cultura de Paz ou de Compliance, parece-nos então, que a relação existente entre os fins colimados por ambos os movimentos, isto é, o Sistemas de Gestão de Compliance e o Direito à Paz estão intrinsicamente ligados, seja pelos movimentos sociais ou pela classificação como direitos fundamentais ou, ainda, pela necessidade de uma mudança comportamental que se solidifica com a educação e a ética. Para além disso, temos ainda que os chamados Sistemas de Gestão de Compliance, enquanto Sistema de Gestão, permitem um melhor controle e capacitação de todos os atores sociais que vão desde pessoas à Organizações (públicas ou privadas). 
Para melhor entender o nexo entre o Compliance e a Paz, mostra-se de grande importância entender a essência, a natureza, a origem e a finalidade dos institutos invocados, pois o fim colimados por ambos tangenciam o bem comum, a paz e uma sociedade livre das mazelas, tanto da corrupção quanto das guerras em seu sentido mais amplo. Afinal, o Compliance não se resume ao combate à corrupção, assim como a Paz também não se esgota na simples concepção de ausência de guerra.

\section{Direito à paz como direito fundamental}

Em 2018 se comemorou os setenta anos da Declaração Universal dos Direitos Humanos (1948). No mesmo ano, especialmente no dia 21 de setembro em que se celebra o Dia Internacional da Paz, António Guterres, Secretário-Geral da Organização das Nações Unidas (ONU), afirmou que os valores contidos na referida Declaração podem assegurar a paz duradoura no mundo, pois "a paz cria raízes quando as pessoas vivem livres da fome, da pobreza e da opressão"2. A fala do representante da ONU demonstra a merecida preocupação com a cultura da paz. Dessa forma, encorajar os países, os cidadãos, as autoridades públicas, entre outras, é o primeiro passo de uma mudança comportamental.

Contudo, não se devem confundir políticas inclusivas com discursos populistas ou até mesmo extremistas, pois isso representa verdadeiro um retrocesso a grandes conquistas relacionadas aos Direitos Humanos ao longo da História.

Segundo a Diretora-Geral da UNESCO (United Nations Educational, Scientific and Cultural Organization), Audrey Azoulay, as barreiras à paz são complexas e íngremes - nenhum país pode resolvê-las sozinho. Fazer isso requer novas formas de solidariedade e ação conjunta, começando o mais cedo possível. Afirma a Diretora que a Boa Governança e a cultura de paz são umas das prioridades da gestão da entidade:

"Establishing a culture of peace and sustainable development are at the heart of UNESCO's mandate. Training and research in sustainable development are among the priorities, as well as human rights education, skills for peaceful relations, good governance, Holocaust remembrance, the prevention of conflict and peace building".

2 ONU - Organização das Nações Unidas - Direitos Humanos são o caminho para a paz duradoura no mundo. [Consultado em: 03 de Março de 2019]. Disponível em: https://nacoesunidas.org/onu-diz-que-direitos-humanos-sao-caminho-para-paz-duradoura-no-mundo/.

3 UNESCO - Peaceday. [Consultado em: o8 de Março de 2019]. Disponível em: https://en.unesco.org/ commemorations/peaceday. 
Nota-se no discurso de duas grandes entidades de representação internacional, uma preocupação em correlacionar os direitos humanos fundamentais com o direito à paz. Isso porque, a paz não deve ser simplesmente conceituada como ausência de guerra, mas sim como verdadeiro direito humano fundamental. Segundo a Assembleia Geral da UNESCO de 1999, Cultura de Paz é "um conjunto de valores, atitudes, tradições, comportamentos e estilos de vida baseados no respeito à vida, ao fim da violência, à prática da não-violência por meio da educação, diálogo e cooperação" 4 . Entende-se, portanto, que a Cultura de Paz é um movimento que aglutina preceitos em busca de um bem comum que é o Direito Fundamental à Paz.

Nesse contexto, a Constituição do Brasil de 1988, em seu artigo quarto prevê que a República Federativa do Brasil se rege nas suas relações internacionais por diversos princípios, entre eles, a defesa da paz e a prevalência dos direitos humanos. Da mesma forma, a Constituição de Portugal de 1976, em diversos artigos, como por exemplo, o artigo sétimo, prevê que o país se empenha no reforço da identidade europeia e no fortalecimento da Ação dos Estados europeus a favor da democracia, da paz, do progresso econômico e da justiça nas relações entre os povos.

Em 12 de novembro de 1984, data intermediária entre as duas constituições citadas acima foi editado um importante diploma internacional, a Declaração sobre o direito dos povos à paz (Adotada pela Assembleia Geral - Resolução 39/11), reafirmando que o propósito principal das Nações Unidas é a manutenção da Paz e da segurança internacional. O diploma em tela reconhece que garantir que os povos vivam em paz é o sagrado dever de todos os Estados. Vejamos:

"1. Proclama solenemente que os povos de nosso planeta têm o direito sagrado à Paz; 2. Declara solenemente que proteger o direito dos povos à paz e promover sua realização é uma obrigação fundamental de todo Estado; 3. Reitera que para assegurar o exercício do direito dos povos à Paz é necessário que a política dos Estados esteja orientada para a eliminação da ameaça de guerra, especialmente da guerra nuclear, à renúncia do uso da força nas relações internacionais e ao acordo pacífico das controvérsias internacionais por meios pacíficos de acordo com a Carta das Nações Unidas; 4. Convoca a todos os Estados e a todas as organizações internacionais para que contribuam com todos os meios para

4 UNESCO - Social and human sciences. Culture of Peace. [Consultado em: 08 de Março de 2019]. Disponível em: http://www.unesco.org/new/pt/brasilia/social-and-human-sciences/culture-of-peace/. 
assegurar o exercício do direito dos povos à paz mediante a adoção de medidas pertinentes nos planos nacional e internacional"5.

Passemos a uma breve digressão acerca da classificação dos direitos fundamentais com o objetivo de asseverar a transladação da paz da terceira para a quinta "geração" de direitos fundamentais. A classifição evolutiva dos direitos fundamentais em gerações foi utilizada por Karel Vasak ${ }^{6}$ em Conferência ministrada em 1979, no Instituto Internacional de Direitos Humanos. Na ocasião ele difundiu a ideia de que os direitos fundamentais não nasceram de uma vez, mas foram sendo afirmados ao longo da evolução histórico-social7, buscando demonstrá-la com base no lema da Revolução Francesa (liberdade, igualdade e fraternidade). Posteriormente, superando-se então a ideia de geração, passou-se a $\operatorname{adotar}^{8}$ a concepção de dimensões dos direitos fundamentais.

Bobbio ${ }^{9}$ propaga a referida classificação em sua obra A Era dos Direitos, discorrendo que os direitos fundamentais, a partir de um perfil histórico, se reduziriam a três gerações ${ }^{10}$ : os direitos de primeira geração ligados aos direitos de liberdade; os de segunda geração relacionados com os direitos de igualdade; e os direitos de terceira geração vinculados aos direitos de fraternidade. Mais adiante serão abordadadas também as novas classificações acerca da quarta, quinta e sexta dimensões dos direitos fundamentais.

Em virtude de representar uma evolução histórica, a expressão geração deu a entender que haveria uma substituição gradativa dos direitos, o que na prática não ocorria, daí tal termo ter sido rechaçado. Em oposição a concepção de gerações surgiu a terminologia dimensão, que passa a ideia de que os novos direitos são acrescidos aos demais, havendo um somatório de direitos fundamentais e não a substituição de uma geração pela outra.

$\mathrm{Na}$ visão ocidental dos direitos fundamentais, a primeira geração engloba os direitos individuais e os direitos políticos ${ }^{11}$. O primeiro diz respeito à proteção das pessoas contra o poder do Estado e o segundo, expressam os direitos de nacionalidade e os de participação política, que se sintetizam no direito de votar e ser votado e ao assumir uma natureza nega-

5 ONU - Organização das Nações Unidas - Direito à Paz. [Consultado em: 08 de Março de 2019]. Disponível em: http://www.dhnet.org.br/direitos/anthist/marcos/hdh_dec_onu_direito_paz.pdf.

6 SARLET, Ingo Wolfgang - A eficácia dos direitos fundamentais. Porto Alegre: Livraria do Advogado, 2003, p. 82.

7 OMMATI, José Emílio Medauar - Uma teoria dos direitos fundamentais. 5.. ${ }^{\mathrm{a}}$ ed. Rio de Janeiro: Lumen Juris, 2018, p. 37.

8 SARLET, Ingo Wolfgang - Mark Tushnet e as assim chamadas dimensões ("gerações") dos direitos humanos e fundamentais: breves notas. In Rei - Revista Estudos Institucionais. Rio de Janeiro. ISSN 2447-5467. V. 2, N. ${ }^{\circ}$ 2, 2017, p. 489-516.

9 BOBBIO, Norberto - A era dos direitos. 7.. ${ }^{\mathrm{a}}$ reimpr. Rio de Janeiro: Elsevier, 2004, p. 79.

10 Atualmente já se encontra na doutrina a classificação de direitos fundamentais de sexta dimensão.

11 BARROSO, Luís Roberto - Curso de direito constitucional contemporâneo: os conceitos fundamentais e a construção do novo modelo. 5.. ${ }^{a}$ ed. São Paulo: Saraiva, 2015, pp. 212-213. 
tiva, são também denominados de direitos negativos (obrigação de não-fazer). Essa dimensão de direitos surgiu ao final do século $\mathrm{XVIII}^{12}$, com as diversas revoluções da sociedade burguesa em face dos governos oligárquicos, e com os deslocamentos das relações feudais em decorrência da emergência do mercado ${ }^{13}$.

Segundo Bonavides ${ }^{14}$, os direitos de segunda dimensão são os direitos sociais, culturais e econômicos (referidos normalmente como direitos sociais) e, ainda, os direitos coletivos ou de coletividades, introduzidos no Constitucionalismo das distintas formas de Estado Social, depois que germinaram por obra da ideologia e da reflexão antiliberal do século XX. Também chamados de liberdades positivas (obrigação de fazer), pois buscam assegurar o princípio da igualdade material entre o ser humano, os direitos de segunda dimensão (educação, saúde, seguridade social, etc.) surgiram em decorrência dos graves problemas sociais e econômicos originados pela industrialização realizada sob o signo do laissez faire ${ }^{15}$, que fortaleceu a clássica expressão adotada por Hobbes ${ }^{16}$ : "o homem é o lobo do homem".

Os direitos de terceira dimensão são os direitos de titularidade transindividual (coletiva ou difusa $)^{17}$, pois pelo fato de se desprenderem, da figura do homem-indivíduo como seu titular, acabam por se destinar à proteção de grupos humanos (povo, nação).

Da terceira dimensão em diante não há consenso na doutrina sobre a inclusão de direitos de quarta, quinta e, até mesmo, sexta dimensão de direitos fundamentais.

Compartilhamos do entendimento de que os direitos de quarta dimensão tratam do futuro respeito à cidadania (imprescindíveis para a realização efetiva da globalização política) e, portanto, compreendem o direito à democracia, informação e pluralismo (político, religioso, jurídico e cultural) e de normatização do patrimônio genético.

No que se refere à existência dos direitos de quinta dimensão, pode-se invocar o direito à paz como seu legítimo representante.

Por fim, o direito fundamental de acesso à água potável, pelo fato de ser necessária à existência humana e a outras formas de vida e, por conseguinte, necessitar de tratamento prioritário da sociedade e do poder público, vem sendo classificado como direito de sexta dimensão.

12 FERNANDES, Bernardo Gonçalves - Curso de direito constitucional. 9.. ed. Salvador: Juspodivm, 2017 , p. 325.

13 TUSHNET, Mark - Notas sobre alguns aspectos da taxonomia das "gerações" de direitos. In Rei - Revista Estudos Institucionais. Rio de Janeiro. ISSN 2447-5467. V. 2, N. ${ }^{\circ}$ 2, 2017, p. 486-497.

14 BONAVIDES, Paulo - Curso de direito constitucional. 15.. a ed. São Paulo: Malheiros, 2005, p. 564.

15 A expressão francesa laissez-faire, cuja tradução literal para a língua portuguesa significa "deixar fazer" é considerada como um símbolo da economia liberal defendida pelo capitalismo.

16 Thomas Hobbes (1588-1679), autor do Leviatã, foi o responsável por divulgar a famosa frase "O homem é o lobo do homem".

17 SARLET, Ingo Wolfgang; MARINONI, Luiz Guilherme; MITIDIERO, Daniel - Curso de direito constitucional. 6.. ${ }^{\text {e }}$ d. São Paulo: Saraiva, 2017, p. 89. 
Retomando ao foco principal do presente artigo, o direito à paz, percebe-se que Karel Vasek ao classificar a paz como direitos de terceira geração, isto é, como direitos ligados à fraternidade, não desenvolveu a concepção no contexto de norma jurídica constitucional. Bonavides $^{18}$ afirma que o direito à paz é direito natural dos povos, que esteve em "estado de natureza no contratualismo social de Rousseau ou que ficou implícito como um dogma na paz perpétua de Kant".

\section{A origem da era do compliance como instrumento de transformação comportamental}

A chegada do Compliance nos diversos países não encontra uma identidade cronológica, pois na verdade, não estamos tratando de um instituto recém-criado. Há anos atrás começaram a surgir os estudos sobre Compliance ${ }^{19}$, especialmente com respaldo nas normas editadas nos Estados Unidos da América na década de 70.

A propagação do Compliance pelo mundo através das normas editadas pela International Standardization Organization vem possibilitando uma mudança comportamental em vários segmentos. Contudo, essa efetiva mudança é o maior desafio a ser enfrentado. Ao nosso sentir, corrupção, violência, drogas e pobreza são os principais ingredientes de desarticulação do movimento de busca da paz.

No Brasil, por exemplo, o tema, até pouco tempo era desconhecido, mas a operação intitulada Lava-Jato passou a povoar as mídias brasileiras, difundindo informações para a sociedade, inaugurando no Brasil a Era do Compliance e do combate efetivo à corrupção que já estava consolidada nos EUA. No continente europeu a norma editada pelo Reino Unido, intitulada United Kingdom Bribery Act já cumpria esse papel desde o ano de 2010.

É cediço que a mazela da corrupção não é nova, tampouco exclusiva de algum país, mas os esquemas perniciosos que dominaram as regulações negociais entre o setor público e privado impactaram de tal forma a sociedade que, passou a ser considerada uma prioridade.

O combate aos ilícitos envolvendo funcionários públicos estrangeiros sempre constituíram uma grande preocupação da comunidade internacional, sobretudo, no que se refere ao seu impacto nas relações de mercado. Da mesma forma é indiscutível que, se uma organização se envolver em um escândalo de corrupção (ou suborno), os reflexos acarretarão

18 BONAVIDES, Paulo - A quinta dimensão dos direitos fundamentais. [Consultado em: 08 de Março de 2019]. Disponível em: http://www.ufjf.br/siddharta_legale/files/2014/o7/Paulo-Bonavides-A-quinta-gera\% $\mathrm{C}_{3} \% \mathrm{~A} 7 \% \mathrm{C}_{3} \% \mathrm{~A} 30$-de-direitos-fundamentais.pdf, p. 10.

19 Para se aprofundar no tema recomendamos a leitura de nossa obra: CARNEIRO, Claudio; SANTOS, Milton de Castro de - Compliance e Boa Governança (Pública e Privada). Curitiba: Juruá e Editora FGV, 2018. 
um prejuízo à sua imagem reputacional. Para evitar tais ocorrências, alguns países, como por exemplo a Alemanha, permitiram até a década 1990, a dedução na esfera tributária do pagamento de propina paga às autoridades estrangeiras.

Um grande passo dado na História foi a assinatura da Convenção sobre o Combate à Corrupção de Funcionários Públicos Estrangeiros em Transações Comerciais, que tratou da adequação da legislação dos Estados signatários às medidas necessárias à prevenção e ao combate dessa ilicitude no âmbito do comércio internacional. Foi dessa forma que, com base no Foreign Corrupt Pratices Act (FCPA) de 1977, a OCDE ${ }^{20}$, no ano de 1997, elaborou a Convenção da $O C D E$, ratificada pelo Brasil ${ }^{21}$.

As normas International Standartization Organization ${ }^{22}$, especialmente as que tratam do Sistema de Gestão de Compliance e do Sistema de Gestão Antissuborno, foram essenciais para projetar para todo o mundo a necessidade de implementação dos Programas de Compliance ou de Integridade (que para alguns são expressões sinônimas) ${ }^{23}$.

Não por acaso, o Brasil se alinhando a uma tendência mundial de enfrentamento a corrupção e ao suborno, promulgou sua Lei Anticorrupção (Lei 12.846/13), seguida do Decreto regulamentador n. ${ }^{\circ} 8.420 / 15$, valendo-se da ancestralidade dos diplomas internacionais, sobretudo o Foreign Corrupt Pratices Act (1977) e o United Kingdom Bribery Act (2010).

Não há dúvidas que a adoção de um Sistema de Gestão de Compliance e Antissuborno, além de necessário passa a ser um antídoto eficaz para evitar complicações futuras e, ainda, permite uma vantagem competitiva de mercado e proporciona a sustentabilidade da organização.

É importante ressaltar que para se definir um Programa Compliance, ao menos ao que se propõem as normas internacionais, não se deve levar em conta apenas o conceito penal de corrupção, mas sim uma concepção mais ampla que envolve o GRC (Governança, Risk Assessment e Compliance em sentido amplo). Significa dizer que não dever ser visto apenas como uma norma anticorrupção, mas sim um sistema de gestão que perpassa por diversos

20 OCDE em português significa Organização para a Cooperação e Desenvolvimento Econômico. Trata-se de uma Organização com sede em Paris que foi idealizada em 1947 com o principal objetivo de cooperar na implementação de um plano financeiro Norte-Americano que consistia em ajudar a Europa pós II Guerra Mundial (plano Marshall).

21 A OCDE elaborou um guia para empresas multinacionais, que contém recomendações dos governos para as empresas estabelecidas em mais de um país.

22 A ISO é uma das maiores organizações normatizadoras do mundo, tendo sido criada a partir da união da International Federation of the National Standardizing Associatitons e a United Nations Standards Coordinating Committee, começando a funcionar em 1947. A ISO é uma das organizações mais confiáveis e de maior credibilidade no mercado quando o tema é normatização de técnicas em escala global e, por isso, está em cerca de 160 países.

23 Um Sistema de Gestão nada mais é do que um conjunto de normas harmonizadas com o objetivo de atingir uma determinada finalidade. Dessa forma, o Compliance e Antissuborno são espécies distintas de sistemas de gestão. 
setores relevantes de uma Organização pública ou privada, ou seja, deve alcançar todos os stakeholders envolvidos no processo ${ }^{24}$.

\section{A. Aspectos históricos e normativos relevantes}

A evolução internacional ocorreu ao longo das décadas, mas o embrião sobre Compliance teve sua origem nos EUA. Em 1906, com a promulgação do Food and Drug Act, o governo norte-americano criou um modelo de fiscalização centralizado, como forma de regular as atividades relacionadas à saúde alimentar e ao comércio de medicamentos, contudo, foi devido às instituições financeiras que o Compliance avançou.

Alguns fatos históricos relevantes contribuíram para a criação e o amadurecimento de diversas normas ao longo de décadas. Dessa forma, conhecer a legislação internacional e a sequência cronológica de fatos relevantes, mostra-se imprescindível para a implementação de Programas de Compliance de alto nível.

À título de ilustração, podemos citar alguns momentos importante ao longo da história: Em 1913 foi criado do Banco Central Americano (Board of Governors of the Federal Reserve) para implementar um sistema financeiro mais flexível, seguro e estável; No ano de 1945, através das Conferências de Bretton Woods foi criado o Fundo Monetário Internacional e do BIRD (Banco Internacional para Reconstrução e Desenvolvimento) , com o objetivo básico de zelar pela estabilidade do Sistema Monetário Internacional; Em 1960 a SEC (Security Exchange Commission) passa a insistir na contratação de Compliance Officers para criar procedimentos internos de controles, treinar e monitorar pessoas com o objetivo de auxiliar as áreas de negócios a ter a efetiva supervisão; Em 1988 foi estabelecido o primeiro Acordo de Capital da Basiléia, estabelecendo padrões para a determinação do capital mínimo das instituições financeiras. Em 1998 foi publicada no Brasil a Lei 9.613, que dispôs sobre crimes de lavagem ou ocultação de bens, a prevenção da utilização do Sistema Financeiro Nacional para atos ilícitos previstos na referida lei e cria o Conselho de Controle de Atividades Financeiras (COAF); No ano de 1999 destacamos a criação do Eastern and Southern Africa Anti-Money Laundering Group.

Em 2002, a falha nos Controles Internos e a ocorrência de fraudes contábeis levaram à concordata da Wordcom. Ato contínuo, o Congresso Americano publica a famosa "Sarbanes-Oxley Act", que determinou às empresas registradas na SEC a adoção das melhores práticas contábeis, independência da Auditoria e criação do Comitê de Auditoria; Em 2006 foi edi-

24 Pode acontecer de que nenhuma lei ou regulamento sejam descumpridos, mas por algum motivo uma atitude ou ação tomada gere um risco para a Organização. Como exemplo, uma propaganda considera preconceituosa pode acabar com a pretensão de crescimento da empresa, sepultando os valores das ações, ou seja, um comercial de segundos pode acabar com um projeto de anos. 
tado o Decreto n. 5.687 que promulgou a Convenção das Nações Unidas contra a Corrupção, adotada pela Assembleia Geral das Nações Unidas ${ }^{25}$. O rol apresentado é meramente exemplificativo, pois muitos outros diplomas legais foram editados em todo o mundo.

Por todo o exposto até agora, é possível concluir que o mundo está em consonância com a Era do Compliance ${ }^{26}$. Apesar dos EUA terem começado na década de setenta e, por isso, já contarem com uma estrutura mais sedimentada que outros países, a base cultural já começa a ser propagada em todos os continentes.

\section{B. O FCPA O U.K. BRIBERY}

Poderíamos citar várias outras normas que tratam do tema, mas preferimos focar em duas leis que se tornaram emblemáticas no cenário mundial: o FCPA e o U.K. Bribery Act. O Foreign Corrupt Practices Act (FCPA) é uma lei federal americana, de 1977, que visa combater a corrupção. Por outro lado, o U. K. Bribery Act, nasceu na Inglaterra e entrou em vigor dia o1 de julho de 2011, sendo considerada uma das legislações mais duras do mundo sobre o tema.

O FCPA nasceu com o objetivo de combater o suborno de funcionários públicos estrangeiros e, com isso, buscar garantir ${ }^{27}$ a integridade do mercado de capitais dos EUA, tanto quanto devolver a confiança da sociedade no sistema corporativo daquele país. A lei americana dispõe de uma característica pouco mencionada, mas que a diferencia, essencialmente, de outros diplomas. Isto porque, o FCPA responsabiliza a corrupção ativa, ou seja, preocupa-se com o ato do corruptor, não trazendo, em seu bojo normativo, consequências para a corrupção passiva.

Quanto à competência e sua aplicabilidade, o referido diploma alcança qualquer cidadão americano, subsidiária americana ou estrangeira (inclusive brasileira) em solo americano que tenha capital americano e empresas estrangeiras que tenham negócios ou conexões com os EUA, além de outras situações específicas.

25 No exemplo brasileiro, no ano de 2013, o Brasil, alinhado a uma tendência mundial de enfrentamento da corrupção, promulgou sua Lei Anticorrupção (Lei 12.846/13), seguida do seu decreto regulamentador (Dec. 8.420/15) e, posteriormente, a Lei 13.303/16 chamada de Lei das Estatais.

26 No exemplo brasileiro também foram editadas as seguintes normas: a) Código de Ética Profissional do Servidor Público Civil do Poder Executivo Federal (Decreto 1.171, de 22 de Junho de 1994); b) Lei de Responsabilidade Fiscal (Lei Complementar 101, de 4 de maio de 2000); c) Programa Nacional de Gestão Pública e Desburocratização (GesPública), instituído em 2005; d) Lei n. ${ }^{\circ}$ 12.527, de 18 de novembro de 2011, chamada de Lei do Acesso a Informação; e) Lei n. ${ }^{\circ} 12.813$, de 16 de maio de 2013, chamada de Lei de Conflito de Interesses no exercício de cargo ou emprego do Poder Executivo Federal; f) Lei n. ${ }^{\circ} 12.846$ de $1 .^{\circ}$ de agosto de 2013, intitulada Lei Anticorrupção, com seu respectivo Decreto regulamentador de n. ${ }^{\circ} 8.420$ de 18 de março de 2015 e; g) Decreto 8.793 de 29 de junho de 2016 que institui a Política Nacional de Inteligência. Vale ressaltar que o rol não é exaustivo, pois dispositivos de outros diplomas também devem ser invocados para compor todo o ordenamento pertinente à matéria.

27 STELLMACH, William - Foreign Corrupt Practices Act. [Consultado em: 08 de Março de 2019]. Disponível em: http://www.justice.gov/criminal/fraud/fcpa/ 
Vale ressaltar que a eficácia dessa norma americana sobre empresas situadas em outros países, poderia ser considerada algo aviltante face ao princípio da territorialidade e da soberania nacional, pois em tese não estaria submetida à jurisdição americana. Contudo, se uma empresa exporta mercadorias para os EUA, mas de forma ilegal, tal fato, por si só, já a enquadra como violadora da FCPA e poderá sofres as sanções nela prevista. Com base nesse exemplo, é possível afirmar que a aplicabilidade da FCPA a empresas domiciliadas em outros países é real,

Com o objetivo de promover a responsabilização e aplicação do FCPA, existem dois órgãos de atuação: Securities Exchange Commission (SEC) e o Department of Justice (DOJ). Enquanto o DOJ possui competência civil e criminal para investigar e deflagrar ações penais (criminal law enforcement), relativamente às violações do FCPA, a SEC detém competência civil e administrativa (civil law enforcement).

Em apertada síntese, podemos dizer que o FCA possui, entre outras, as seguintes atribuições: a) investigar pessoas físicas ou jurídicas; b) regulação das condutas relacionadas à comercialização de produtos financeiros; c) determinar que as empresas retirem imediatamente promoções enganosas e que publiquem tais decisões.

Partindo para o U.K. Bribery Act, percebe-se que esta legislação, no que se refere a local e extraterritorialidade, engloba empresas do Reino Unido que fazem negócio local e no exterior, empresas estrangeiras com operações no Reino Unido, funcionários públicos locais e estrangeiros e o setor público e privado de modo geral.

Vale ressaltar que o Reino Unido foi bastante criticado por suas práticas negociais. A uma pela possibilidade de dedução no imposto de renda da propina ofertada em outros países (com empresas ou governos estrangeiros) à semelhança do que previa a legislação alemã. A duas pela demora na edição de uma lei de combate à corrupção. Diante desse cenário, o governo Britânico editou o Bribery Act com o objetivo de dar uma resposta social às críticas pela inércia legislativa no combate da corrupção.

O papel que é desempenhado pelo SEC (Security Exchange Commission) nos EUA, no Reino Unido é executado pelo SFO (Serious Fraud Office) que possui atribuição de investigar e responsabilizar atos de corrupção, com atuação na Inglaterra, País de Gales e Irlanda. Considerado um órgão independente e rigoroso, o SFO está vinculado diretamente à Procuradoria Geral do Reino Unido, podendo requerer a qualquer pessoa, sejam elas físicas ou jurídicas, que forneçam documentos relevantes, inclusive sigilosos, ou que respondam perguntas sobre quaisquer assuntos relevantes, confidenciais ou não, para o caso analisado.

Por fim, enquanto o FCPA se subdivide em duas partes, o UKBA prescreve quatro categorias de infrações distintas: a) o ato de oferecer vantagem indevida; b) o ato de aceitar van- 
tagem indevida; c) o suborno de funcionário público estrangeiro e; d) a falha na prevenção de corrupção por uma pessoa jurídica.

Valendo-se de experiências adquiridas em outros países, o fato é que as fraudes passaram por extraordinária modificação e sofisticação. Se antes era praticado por um processo isolado e individual de um agente, hoje, a questão transformou em complexos esquemas dotados de tecnicidade, que somente podem ser combatidos com uma tecnologia da informação e dos meios eletrônicos mais modernos ${ }^{28}$.

As crises econômicas são fatores relevantes para equilíbrio econômico-financeiro das empresas. Dessa forma para superar uma crise ou, simplesmente, estabilizar o cenário financeiro de uma Organização (privada ou pública), um bom Programa de Compliance/Integridade é fundamental, pois é capaz de identificar divergências entre o que se paga e o que deveria ser pago, adequando a Organização antes que a mesma sofra sanções administrativas, judiciais e pecuniárias, pois talvez ela possa pagar a diferença de tributos e continuar normalmente a sua operação, mas uma multa acabaria com o seu caixa, levando-a a falência.

Muitas fraudes cometidas pelas Organizações perpassam por fraudes fiscais ${ }^{29}$, seja para criar sistemas de "caixa dois" para dar lastro financeiro paralelo para encobrir os esquemas de corrupção ou para sonegar tributos.

Por isso, o canal de denúncias é classificado como um dos pilares de um Programa de Compliance e, atualmente, por força dos contratos e exigências realizadas por organizações transnacionais em todo o mundo, sua implantação se tornou uma realidade necessária.

Percebe-se então, que todo o contexto apresentado, seja para o setor público ou privado ou, ainda, para as relações internacionais envolvendo estados soberanos, há que se ter um modelo de Boa Governança de modo que a Cultura do Compliance se propague de maneira eficiente e eficaz. Basta citar que já houve caso de organização não governamental internacional de ajuda humanitária estar envolvida em grandes escândalos de fraudes e corrupção.

\section{A boa governança e a cultura de paz}

Com visto anteriormente a governança é uma peça fundamental que integra o Compliance na estrutura internacional denominada GRC (Governança, Risk Assessment e Compliance em sentido amplo). Logo, ao se falar em Boa Governança estar-se-á falando em Compliance.

28 SOARES, Inaldo de Vasconcelos - Fraudes nas Gestões Públicas e Privadas. Brasília: Brasília Jurídica. 2005, p. 53. 29 Sobre questões tributárias e fiscais, recomendamos nossas obras: CARNEIRO, Claudio - Curso de Direito Tributário e Financeiro. 8.. ${ }^{a}$ ed. São Paulo: Saraiva, 2019; CARNEIRO, Claudio - Processo Tributário (Administrativo e Judicial). 6.. ${ }^{a}$ ed. São Paulo: Saraiva, 2019; CARNEIRO, Claudio - Impostos Federais, Estaduais e Municipais. 7.. ${ }^{\text {e }}$ d. São Paulo: Saraiva, 2019. 
A concepção de Boa Governança, nos dias atuais, deve ser tratada como verdadeiro direito fundamental, e não como mera recomendação ao administrador, seja ele público ou privado, pois o mau governo, seja por escolhas indevidas por seus administradores ou simplesmente por atos de corrupção ou suborno, acaba por comprometer direitos assegurados nas Cartas Constitucionais e, com isso, andar na contramão da evolução do Constitucionalismo Contemporâneo ${ }^{30}$.

A alegação bastante frequente de escassez de recursos torna imprescindível que se dê um destino cada vez mais responsável ao orçamento disponível, revelando-se absolutamente incompatível com a ordem de direitos trazida pela Constituição, a má governança ou uma gestão imoral ou improba.

A influência de leis estrangeiras é cada vez mais forte em vários países. O Compliance que traz em sua essência normas de governança, gestão de riscos e combate à corrupção e ao suborno pode ser considerado uma importante ferramenta para o avanço do (Neo) constitucionalismo no país, pois visa a ampliar os instrumentos de controle e conferir uma maior transparência da gestão dos recursos públicos e, com isso, aumentar a efetividade dos Direitos Fundamentais e, em especial, os sociais que exigem um maior dispêndio de recursos.

É importante destacar que por trás de toda Constituição, em especial as democráticas, não existe apenas uma técnica legislativa, ou um formalismo estéril, mas sim um movimento, uma conquista de pessoas para novos avanços políticos e sociais. Nesse sentido, surge um sentimento constitucional no país e na sociedade que deve ser efetivamente alcançado, não deixando essa discussão meramente para o plano teórico ou utópico, mas levando-a principalmente para a atuação prática, pois o marco filosófico do "novo" constitucionalismo é o pós-Positivismo. Assim, o debate sobre sua caracterização situa-se na confluência das duas grandes correntes de pensamento que oferecem paradigmas opostos para o Direito, mas que, por vezes, são singularmente complementares: o Jusnaturalismo e o Positivismo. Acreditamos que nessa onda democrática em que se tem novas concepções de aplicação das constituições é que se inserem a Cultura da Paz e do Compliance. Significa dizer que as novas dimensões de direitos fundamentais devem se compatibilizar com o novo movimento constitucional que aflora não somente sob o ponto de vista teórico, mas sobretudo, na aplicabilidade prática dos direitos humanos.

No plano teórico, três aspectos passaram a ser importantes no que se refere à aplicação do Direito Constitucional: a força normativa da Constituição; o desenvolvimento de

30 Utilizamos essa expressão com os devidos fundamentos expostos na obra CARNEIRO, Claudio Neoconstitucionalismo e Austeridade Fiscal: confronto constitucional-hermenêutico das cortes constitucionais do Brasil e de Portugal. Salvador: Juspodivm, 2017, p. 26. 
uma nova dogmática da interpretação constitucional e, com isso, a expansão da jurisdição constitucional. Contudo, no campo prático, e esse é o nosso principal questionamento, não percebemos nenhuma mudança significativa.

Caminhando com Holmes, Sustein ${ }^{66}$ e Posner ${ }^{67}$, é claro que sabemos a importância do orçamento de um país para fazer frente às despesas. Não sustentamos aqui uma postura anarquista ou de total liberalidade fiscal e, por isso, corroboramos com o entendimento de $S_{\text {Silva }}^{31}$, ao afirmar que o princípio da separação dos Poderes e a competência de dispor do orçamento não são ideias absolutas, pois sofrem limitações constitucionais, nem são fins em si mesmos, mas meios para o controle do Poder Estatal e garantia dos direitos individuais. Aliás, o objetivo é exatamente procurar mostrar a relação existente entre a questão orçamentária e a absorção dessa demanda populacional que, ato contínuo, reflete na concretização de direitos fundamentais. Daí a importância de o Compliance e o direito à Paz serem analisados à luz do movimento Neoconstitucionalista, pois ficou provado através dos últimos escândalos noticiados que a corrupção subtraiu parte dos recursos públicos que seriam destinados aos serviços públicos essenciais, melhor estrutura na saúde e na educação etc. Nesse sentido, as normas de Compliance precisam ser aplicadas à luz da ponderação desses interesses, um dos atributos do Neoconstitucionalismo.

\section{A. Governança pública}

É possível afirmar que a origem da expressão governança está associada ao momento em que organizações deixaram de ser geridas por seus proprietários e passaram por delegação a ser administradas por terceiros.

Para Berle e Means ${ }^{32}$, que desenvolveram um dos primeiros estudos acadêmicos tratando de assuntos correlatos à governança, é papel do Estado regular as organizações privadas. Nessa mesma linha, em 1934 foi criada, nos Estados Unidos, a U.S. Securities and Exchange Comission, organização que, ainda hoje, no contexto americano, é responsável por proteger investidores, garantir a justiça, a ordem e a eficiência dos mercados e facilitar a formação de capital. Anos depois, no começo da década de 90, momento histórico marcado por crises financeiras, o Banco da Inglaterra criou uma comissão para elaborar o Código das Melhores Práticas de Governança corporativa, trabalho que resultou no Cadbury Report. Em 1992, o Committee of Sponsoring Organizations of the Tread-way Commission - COSO publicou o Internal control - integrated framework. Anos mais tarde, em 2002, depois de escândalos envolvendo demonstrações contábeis fraudulentas ratificadas por empresas de auditorias, publicou-

31 SILVA, Sandoval Alves da - Direitos sociais: leis orçamentárias como instrumento de implementação. Curitiba: Juruá, 2007, p. 97.

32 BERLE, A.; MEANS, G. - The modern corporation and private property. New York: MacMillan, 1932, p. 12. 
-se, nos Estados Unidos, a Lei Sarbanes-Oxley, cujo objetivo era melhorar os controles para garantir a fidedignidade das informações constantes dos relatórios financeiros. No mesmo ano, com vistas a apoiar a investigação independente e induzir à melhoria da governança, fundou-se o European Corporate Governance Institute - ECGI. Em 2004, o COSO publicou o Enterprise risk management - integrated framework, documento que ainda hoje é tido como referência no tema gestão de riscos.

Nos anos que se seguiram, dezenas de países passaram a se preocupar com aspectos relacionados à governança e diversos outros códigos foram publicados. Atualmente, o G8 (reunião dos oito países mais desenvolvidos) e organizações como o Banco Mundial, o Fundo Monetário Internacional - FMI e a Organização para Cooperação e Desenvolvimento Econômico - OCDE dedicam-se a promover a governança.

À título de exemplo, o Instituto Brasileiro de Governança Corporativa - IBGC, desde então, lançou versões do Código das melhores práticas de governança corporativa, documento que define quatro princípios básicos de governança aplicáveis ao contexto nacional: transparência, equidade, prestação de contas e responsabilidade corporativa. Segundo o IBGC, apesar de o código ter sido desenvolvido, primariamente, com foco em organizações empresariais, ao longo daquele documento foi utilizado o termo "organizações", a fim de torná-lo o mais abrangente possível e adaptável a outros tipos de organizações, como Terceiro Setor, cooperativas, estatais, fundações e órgãos governamentais, entre outros.

No tocante à Administração Pública, trazendo posições doutrinárias do direito comparado, Civantos ${ }^{33}$ recomenda as seguintes medidas para se aplicar o princípio do Bom Governo:

"Desarrollar uma guía explicativa sobre el tipo de cláusulas a incluir em los contratos, qué formatos dar a las contrataciones que incluyam estas cláusulas y sobre la involucración de técnicos propios o externos de medioambiente, inserción social, ámbito laboral.... a la hora de evaluar el cumplimiento de las cláusulas y requerimientos introdu-cidos em los contratos. Incluir este tipo de cláusulas sociales, medioambientales, etc, em la contratación pública sin menoscabo de los princípios de eficiencia y eficacia ni de la relación calidad-precio que há de regir la gestión del gasto público".

33 CIVANTOS, Óscar Álvarez - Las claves del Buen Gobierno em la Administración Pública. Granada: Comares, 2010, p. 7. 
Caminhando ainda pelo Direito Comparado, compartilhamos o entendimento de Villanueva ${ }^{34}$ sobre gestão estratégica e gestão de qualidade:

"El eslabón que enlaza la estratégia con la calidad y que lleva la planeación/ gestión estratégica a transcender sus fronteras y empal-mar directamente com la gestión de calidad es la creación de valor para el cliente o usuário. La generación de valor es el punto de en-cuentro y engarce de las dos gestiones. La estrategia concibe el produto o resultado de valor que una organización debe producir para sus clientes y sociedade a fin de alcanzar o mantener su rele-vancia social y posicionamiento em su campo de actividad, mientras la gestión de calidad se encarga de assegurar y controlar que los productos o resultados posean establemente los atributos exigidos que generan el valor deseado".

Não há dúvida que o modelo de gestão do novo século sofreu adaptações evolutivas que se distanciam dos modelos anteriores. A participação da sociedade na tomada de decisões, especialmente no que se refere às políticas públicas, mostra-se cada vez mais necessária. Almeida ${ }^{35}$ ao abordar a governança colaborativa democrática em Políticas Públicas afirma que:

"Nesse sentido, alguns fatores e variáveis críticos influenciam e o modelo de governança adotado irá ou não produzir uma colaboração bem-sucedida com resultados efetivos. Dentre esses fatores, destacam-se o diálogo face a face, a construção de confiança e o desenvolvimento do compromisso e da compreensão comuns entre os atores envolvidos".

Nesse modelo de governança proposta pelo autor ${ }^{138}$, isto é, colaborativa democrática, observa-se a preocupação em articular participação, diálogo e cooperação e, ainda, "promover condições de accountability e de reestruturação dos mecanismos de decisão por meio de estímulos ao envolvimento da participação social organizada no ciclo das políticas públicas e do planejamento estatal".

A concepção de Boa Governança transcende a uma ação pontualmente posta; o Direito do Século XXI busca o controle finalístico do Estado emanado pela Constituição. No dizer 
de Valle ${ }^{36}$ Boa Administração resulta de "um vasto conjunto de variáveis que têm em conta a função administrativa, como atividade orientadora e executora de uma plêiade de ações que guardam entre si relações de interdependência e, por vezes, retroalimentação".

Segundo Guerra ${ }^{37}$, o Estado Gerencial que envolve a Administração Pública caracteriza-se pela existência de formas modernas de gestão pública "modificando critérios de aplicação do controle de serviços públicos, as relações estabelecidas entre o Poder Público e seus servidores e alterando, também, a própria atuação da Administração, que passa a enfatizar a eficiência, a qualidade e a efetiva concretização do regime democrático".

Ao longo de décadas presenciamos escândalos que culminaram com diversas formas, mas em todos eles o dinheiro público foi o principal alvo. A História mundial fez com que diversos países passassem a se preocupar com aspectos relacionados à governança. Nesse contexto, várias Organizações Internacionais entraram em cena com o objetivo de promover a Boa Governança, como por exemplo, o Banco Mundial e o Fundo Monetário Internacional (FMI).

Vale ressaltar que as questões afetas à governança vão muito além de matérias afetas a gestão administrativa e, obviamente, seus reflexos, são incalculáveis. A relação entre a boa governança e a cultura de paz superam os limites que muitos podem enxergar. No dizer de Pires $^{38}$, dentre os vários caminhos possíveis:

"A A/RES/71/8, aprovada em 16 de novembro de 2016, elevou a educação à condição de instrumento para fomento de uma participação política construtiva e inclusiva, em sua relação com o desenvolvimento humano, de igual forma que contribuiu para o fortalecimento da democracia, da boa governança e do Estado de direito em todos os níveis".

Percebe-se que, mutatis mutandis, apesar de focar em outro escopo, pois se referiu em seu texto à cultura de paz, o autor invocou um como um dos elementos nucleares, um dos pilares do sistema de gestão que é a educação, que no dizer das normas internacionais assume o contexto de treinamento constante. Significa dizer que, resguardadas as proporções entre a terminologia educação e treinamento, que por óbvio, assume complexidades

36 VALLE, Vanice Regina Lírio do - Direito Fundamental à Boa Administração e Governança. Belo Horizonte: Fórum, 2011, p. 109.

37 GUERRA, Sidney - Supersalários na administração pública municipal: o leading case 2016 de Duque de Caxias. Belo Horizonte: Arraes Editores, 2016, p. 24.

38 PIRES, Alex Sander Xavier - Fluxos migratórios forçados e cultura de paz: um contributo hipotético baseado na educação como pilar da democracia e na solução alternativa à crise do estado assistencialista. In Galileu Revista de Direito e Economia. Lisboa. ISSN 2184-1845. V. XIX, N. ${ }^{\circ} 1,2018$, p. 66-87, p. 67. 
diferentes, nota-se há uma identidade de alguns elementos da cultura de paz e da cultura de compliance. Ao nosso sentir, não se trata de uma mera coincidência, mas sim uma interpelação entre ambos os movimentos. Com essa afirmativa ratificamos o objeto do presente artigo que é, exatamente, estabelecer uma correlação entre o e a cultura de paz tendo como elementos de ligação, a ética, a educação e a boa governança.

O autor ${ }^{39}$ em seu texto, ao presentar um Microssistema Conducente ao Direito à Paz, subdivide em quatro subitens importantes: a) Carta das Nações Unidas: fundamentos, propósitos e princípios inspiradores da declaração sobre o direito à paz; b) Direitos humanos, econômicos, sociais, culturais, civis, políticos e ao desenvolvimento, complementares a formação de um microssistema de direito à paz; c) Instrumentos básicos para fortalecimento do microssistema de direito à paz e; d) Base normativa do direito à paz.

No texto em comento, as bases ideológicas tiveram assento na Carta das Nações Unidas, na Declaração Universal dos Direitos Humanos, no Pacto Internacional de Direitos Civis e Políticos, no Pacto Internacional dos Direitos Econômicos, Sociais e Culturais, na Declaração sobre o Direito ao Desenvolvimento, na Declaração e no Programa de Ação de Viena, na Preparação das Sociedades para Viver em Paz, na Declaração sobre o Direito dos Povos à Paz, e na Declaração e Programa de Ação sobre uma Cultura de Paz; a Declaração sobre o Direito à Paz (A/RES/71/189). Contudo, para efeitos de compliance e antissuborno, poderíamos incluir as normas ISO (International Standardization Organization) n. ${ }^{\circ} 37.001$ que diz respeito ao Sistema de Gestão Antissuborno e n. ${ }^{\circ} 19.600$ que trata do Sistema de Gestão de Compliance e os seguintes tratados: a) Convenção sobre o Combate da Corrupção de Funcionários Públicos Estrangeiros em Transações Comerciais Internacionais da Organização para a Cooperação e Desenvolvimento Econômico (OCDE); b) Convenção Interamericana Contra a Corrupção; c) Convenção das Nações Unidas Contra a Corrupção que inspirou, por exemplo, a lei brasileira n. ${ }^{\circ}$ 12.846/2013, chamada de Lei Anticorrupção.

Indo além, ainda há o Whistleblowing Program que serve de importante ferramenta de modificação comportamental para buscar a integridade pública e corporativa das organizações. É importante ressaltar que embora a tendência seja pensar somente em combater a corrupção quando abordam assuntos relacionados a este programa, contudo, os efeitos positivos do Whistleblowing Program contribuem para um desenvolvimento ético corporativo diante de vários tipos de irregularidades, tais como, ilícitos trabalhistas a práticas societárias que podem prejudicar as organizações diante do mercado de ações ${ }^{40}$.

39 Idem, p. 69.

40 CARNEIRO, Claudio; SANTOS, Milton de Castro de - Compliance e Boa Governança (Pública e Privada). Curitiba: Juruá e Editora FGV, 2018, p. 221. 


\section{B. Governança privada}

A governança privada na essência não se distingue da governança pública, a não ser quanto à finalidade e a algumas particularidades que a Administração Pública possui em razão da sua natureza.

Vale lembrar que as normativas internacionais não se referem a entes públicos e privados de maneira distinta, tampouco faz qualquer distinção das sociedades com ou sem fins lucrativos. Para o modelo internacional padronizado pelas normas da International Standardization Organization (ISO) todos são chamados de Organização.

Essas normas são de aplicabilidade em todo o mundo e não excluem as leis que, porventura, venham a ser editadas no âmbito interno de cada país para fomento ou preservação de direitos fundamentais.

No Brasil, por exemplo, convencionou-se chamar de programa de integridade para a Administração Pública e programa de compliance quando estivermos diante de sistemas de gestão para a iniciativa privada. Dessa forma, há uma falha técnico-terminológica quando leis exigem que uma organização privada tenha implantado um programa de integridade efetivo para que possa contratar com a Administração Pública. Apesar dessa crítica meramente terminológica, vale dizer que não há nenhuma consequência prática em ambas a denominação. Contudo, é importante que se deixe claro que quando a Administração exige do particular a implantação do respectivo programa de integridade, não significa dizer que o próprio ente público solicitante esteja em compliance (ou tenha um programa de integridade próprio. Por isso, entendemos que a integridade para ser efetiva enquanto cultura de compliance, ou seja, um movimento, deve ser exigida do seguinte tripé sem distinções: a) da própria Administração Direta; b) das estatais e; c) da iniciativa privada.

No que se refere à Portugal, não há essa distinção terminológica entre integridade e compliance, pois o país segue com mais rigidez as normativas internacionais.

Dentro de uma Organização de natureza privada, podemos elencar algumas linhas de defesa, a saber: Negócio, Compliance e Auditoria Interna. A primeira linha de defesa é o Negócio, no qual os próprios funcionários devem não só ter conhecimento, mas também gerir a rotina diária de trabalho e os seus riscos. O Compliance é a segunda linha, com a supervisão junto aos órgãos de controle o funcionamento do seu próprio sistema, enquanto a Auditoria Interna é a terceira e última linha, devendo fazer a supervisão de toda a Organização, inclusive da área de Compliance.

Atualmente é cada vez mais frequente encontrar empresas que buscam tomar suas decisões baseadas em dados, é a chamada Data Driven Business. Esse modelo de decisão pode exigir dos gestores outras bases de informações, dessa forma é necessário possuir dados e informações de alta qualidade e credibilidade. 
Controlar os riscos é se antecipar, minimizar os potenciais danos e zelar pelo seu patrimônio. É evidente que só o fato de uma empresa existir, e dependendo da sua atividade, há riscos inerentes aos negócios, mas se os mesmos forem identificados, os prejuízos serão muito menores. A Organização não deve temer os riscos a ponto de impedir o seu funcionamento, paralisar as atividades ou até mesmo nunca tentar algum tipo de negócio, porém, não deve desprezá-los a ponto de ignorar as práticas legais, contratuais e éticas, nenhuma pessoa física ou jurídica está acima de valores e princípios.

O fato é que, no aspecto específico pertinente à governança e ao combate à corrupção e ao suborno, o binômio público-privado deve andar pari passu com todas as exigências normativas e procedimentais, sejam de ordem legal ou organizacional e, da mesma forma, sejam no âmbito interno ou externo e, especialmente nas relações internacionais.

\section{Conclusão}

A relação existente entre a Cultura de Compliance e a Cultura de Paz somente será de fácil entendimento se partirmos das mesmas premissas. Assim, deve se ter como a premissa primeira, a concepção de que a paz será um objetivo inalcançável enquanto os direitos humanos fundamentais não forem respeitados; os direitos fundamentais devem ser considerados como pré-requisitos para a concepção de uma sociedade que proporcione dignidade de todos os indivíduos. Em segundo lugar, que tanto a Cultura de Compliance quanto a Cultura de Paz são movimentos que envolvem toda a sociedade mundial em busca da Boa Governança e o direito à Paz, respectivamente. Em terceiro lugar, que tanto a boa governança quanto o direito à paz vêm sendo classificados como novas dimensões de direitos humanos fundamentais. Como quarta premissa estabelecida no presente texto, deve-se se conceber o Compliance como um sistema de gestão que envolve três pilares, a saber: Governança, Risk Assessment e Compliance em sentido amplo. Da mesma forma, não adotamos no texto a concepção simplista de que a paz é, simplesmente, a ausência de guerra. Por fim, o último axioma é que a Educação é o instrumento de transformação cultural e, portanto, comportamental.

Estabelecidos os pressupostos que serviram de sustentação teórica para a elaboração do presente texto, diversos são os desafios que colocam em teste a capacidade de se promover uma mudança comportamental na sociedade. Mudanças que possam contribuir de maneira efetiva para a redução das desigualdades sociais e econômicas, que combatam à corrupção, a miséria e a pobreza e, ao fim, possam agregar valores para a importante busca pela paz mundial. 
Apesar de entendermos que a responsabilidade para o alcance desses direitos fundamentais deve ser solidária entre a sociedade e as autoridades públicas, não há dúvida que o Poder Público tem uma parcela mais significativa face à participação efetiva do Estado, sobretudo quando se tratam de determinados direitos fundamentais que exigem uma ação positiva da Organização estatal. Por isso, para que a concepção de Boa Governança seja entendida e reconhecida como direito humano fundamental deve se colocar a pessoa, os seus direitos e liberdades, como Plano de Estado e de Governo. Dito de outra forma, a educação e a ética são os sustentáculos desses movimentos, pois é muito mais fácil que tais valores sejam trabalhados desde a mais tenra idade do que que promover ações em busca de mudanças comportamentais de uma sociedade já contaminada.

Percebemos que os desafios, de fato, são grandes, mas acreditamos que alguns passos já foram dados e ao se reconhecer o direito à Paz e o Compliance, através da Boa Governança, como direitos humanos fundamentas reforçam os pilares teóricos que invocamos para sustentar a vigência do movimento intitulado de Constitucionalismo Contemporâneo.

Ao lado desses pilares, deve-se buscar incessantemente a aplicabilidade prática de ações, como por exemplo, a implantação de sistemas de gestão efetivos que busquem combater as mazelas que estão contaminando o Século XXI.

\section{REFERÊNCIAS BIBLIOGRÁFICAS}

ALMEIDA, Rafael Alves - Governança colaborativa em políticas públicas. Rio de Janeiro: Tamanduá, 2015.

BARROSO, Luís Roberto - Curso de direito constitucional contemporâneo: os conceitos fundamentais e a construção do novo modelo. 5.. ${ }^{\text {a }}$ ed. São Paulo: Saraiva, 2015.

BERLE, A.; MEANS, G. - The modern corporation and private property. New York: MacMillan, 1932.

BOBBIO, Norberto - A era dos direitos. 7.. ${ }^{\mathrm{a}}$ reimpr. Rio de Janeiro: Elsevier, 2004.

BONAVIDES, Paulo - A quinta dimensão dos direitos fundamentais. [Consultado em: 08 de Março de 2019]. Disponível em: http://www.ufjf.br/siddharta_legale/files/2014/07/Paulo-Bonavides-A-quinta-gera\% $\mathrm{C}_{3} \% \mathrm{~A} 7 \% \mathrm{C}_{3} \% \mathrm{~A} 30$-de-direitos-fundamentais.pdf

BONAVIDES, Paulo - Curso de direito constitucional. 15.. ${ }^{a}$ ed. São Paulo: Malheiros, 2005.

CARNEIRO, Claudio - Curso de Direito Tributário e Financeiro. 8.. ${ }^{a}$ ed. São Paulo: Saraiva, 2019.

CARNEIRO, Claudio - Impostos Federais, Estaduais e Municipais. 7.. ${ }^{a}$ ed. São Paulo: Saraiva, 2019.

CARNEIRO, Claudio - Neoconstitucionalismo e Austeridade Fiscal: confronto constitucional-hermenêutico das cortes constitucionais do Brasil e de Portugal. Salvador: Juspodivm, 2017.

CARNEIRO, Claudio - Processo Tributário (Administrativo e Judicial). 6.. ed. São Paulo: Saraiva, 2019.

CARNEIRO, Claudio; SANTOS, Milton de Castro de - Compliance e Boa Governança (Pública e Privada).

Curitiba: Juruá e Editora FGV, 2018.

CIVANTOS, Óscar Álvarez - Las claves del Buen Gobierno em la Administración Pública. Granada: Comares, 2010.

FERNANDES, Bernardo Gonçalves - Curso de direito constitucional. 9.. ${ }^{\text {a }}$ ed. Salvador: Juspodivm, 2017. 
GUERRA, Sidney - Supersalários na administração pública municipal: o leading case 2016 de Duque de Caxias. Belo Horizonte: Arraes Editores, 2016.

OMMATI, José Emílio Medauar - Uma teoria dos direitos fundamentais. 5.. ${ }^{a}$ ed. Rio de Janeiro: Lumen Juris, 2018.

ONU - Organização das Nações Unidas - Direito à Paz. [Consultado em: 08 de Março de 2019]. Disponível em: http://www.dhnet.org.br/direitos/anthist/marcos/hdh_dec_onu_direito_paz.pdf.

ONU - Organização das Nações Unidas - Direitos Humanos são o caminho para a paz duradoura no mundo. [Consultado em: 03 de Março de 2019]. Disponível em: https://nacoesunidas.org/onu-diz-que-direitos-humanos-sao-caminho-para-paz-duradoura-no-mundo/

PIRES, Alex Sander Xavier - Fluxos migratórios forçados e cultura de paz: um contributo hipotético baseado na educação como pilar da democracia e na solução alternativa à crise do estado assistencialista. In Galileu - Revista de Direito e Economia. Lisboa. ISSN 2184-1845. V. XIX, N. ${ }^{\circ}$ 1, 2018, p. 66-87.

SARLET, Ingo Wolfgang - A eficácia dos direitos fundamentais. Porto Alegre: Livraria do Advogado, 2003.

SARLET, Ingo Wolfgang - Mark Tushnet e as assim chamadas dimensões ("gerações") dos direitos humanos e fundamentais: breves notas. In Rei - Revista Estudos Institucionais. Rio de Janeiro. ISSN 2447-5467. V. 2, N. ${ }^{\circ}$ 2, 2017, p. 489-516.

SARLET, Ingo Wolfgang; MARINONI, Luiz Guilherme; MITIDIERO, Daniel - Curso de direito constitucional. 6.. ${ }^{a}$ ed. São Paulo: Saraiva, 2017.

SILVA, Sandoval Alves da - Direitos sociais: leis orçamentárias como instrumento de implementação. Curitiba: Juruá, 2007.

STELLMACH, William - Foreign Corrupt Practices Act. [Consultado em: 08 de Março de 2019]. Disponível em: http://www.justice.gov/criminal/fraud/fcpa/

TUSHNET, Mark - Notas sobre alguns aspectos da taxonomia das "gerações" de direitos. In Rei - Revista Estudos Institucionais. Rio de Janeiro. ISSN 2447-5467. V. 2, N. ${ }^{\circ}$ 2, 2017, p. 486-497.

UNESCO - Peaceday. [Consultado em: 08 de Março de 2019]. Disponível em: https://en.unesco.org/ commemorations/peaceday

UNESCO - Social and human sciences. Culture of Peace. [Consultado em: 08 de Março de 2019]. Disponível em: http://www.unesco.org/new/pt/brasilia/social-and-human-sciences/culture-of-peace/

VALLE, Vanice Regina Lírio do - Direito Fundamental à Boa Administração e Governança. Belo Horizonte: Fórum, 2011.

VILLANUEVA, Luis F. Aguilar - Gobernanza y Gestión Pública. México: FCE, 2006. 